\title{
RESPOSTA À QUALIDADE DE LUZ COMO ESTRATÉGIA PARA ESTABELECIMENTO DE Bidens gardneri $^{1}$
}

\author{
Josimara Nolasco Rondon ${ }^{4}$, MassanoriTakaki ${ }^{3}$ e Lilian Beatriz Penteado Zaidan ${ }^{4}$
}

\begin{abstract}
RESUMO - O objetivo deste trabalho foi verificar o envolvimento do fitocromo na germinação de aquênios do Bidens gardneri Baker., conhecido como picão preto. Os aquênios foram separados em curtos, médios e longos. Dois experimentos utilizaram apenas aquênios médios devido às diferenças quanto à resposta de germinação na ausência de luz, quando foram armazenados artificialmente no solo de cerrado, em um estudo anterior. A resposta dos aquênios curtos, médios e longos ao aumento da fluência de luz branca foi verificada sob um gradiente de luz branca entre 0 e $46,44 \mathrm{mmol} \mathrm{m}^{-2} \mathrm{~s}^{-1}$ de fluência. A reversão do fitocromo vermelho extremo (Fve) em fitocromo vermelho (Fv) no escuro em aquênios médios recém coletados e os armazenados por 14 meses a $4{ }^{\circ} \mathrm{C}$, que foram embebidos em água por 24 horas e incubados a $35^{\circ} \mathrm{C}$ durante 24,48 e 72 horas no escuro e a germinação foi a $25^{\circ} \mathrm{C}$ no escuro e observada após 15 e 30 dias. Por ultimo, foi construído um gradiente de fotoequilíbrio para cada tamanho e idade de aquênio em placas de petri umedecidos com água destilada, na qual a germinação foi observada a cada dois dias. Em irradiâncias de 0 a $46,44 \mathrm{mmol} \mathrm{m}^{-2} \mathrm{~s}^{-1}$, a germinabilidade dos aquênios longos e médios aumentou com a irradiância, porém os aquênios curtos sempre tiveram baixa germinabilidade. Aquênios médios armazenados, pré-embebidos por $24 \mathrm{~h}$ e incubados no escuro por $24 \mathrm{~h}, 48 \mathrm{~h} \mathrm{e} 72 \mathrm{~h}$ a $35^{\circ} \mathrm{C}$ mantiveram resposta fotoblástica quando a germinação foi observada a cada dois dias e após 15 e 30 dias, portanto não apresentaram reversão de Fve para Fv no escuro. No entanto, aquênios médios recém coletados e submetidos aos mesmos tratamentos tiveram o Fve removido quando incubados por 48 e 72 horas. Estes aquênios mostraram a resposta de fluência muito baixa de luz, quando a germinação foi observada a cada dois dias, sob luz verde. Os resultados indicam que heteroblastismo pode conferir à espécie estratégias diferentes de invasão e sobrevivência no cerrado: em locais com baixa disponibilidade de luz poderá ocorrer a germinação dos aquênios longos, ainda na estação chuvosa, (fevereiro). Enquanto os aquênios curtos podem permanecer armazenados no solo, vindo a germinar apenas no final da estação seca (em setembro). Portanto, o aquênio curto persiste no banco de sementes no solo por sete meses e é o que possibilita o estabelecimento de Bidens gardneri em campos de cerrado e pastagens.
\end{abstract}

Palavras-chave: Luz vemelha extrema, fitocromos, Heteroblastismo e Irradiância.

\section{RESPONSE TO THE QUALITY OF LIGHT AS A STRATEGY FOR ESTABLISHMENT OF Bidens gardneri}

\begin{abstract}
The objective of this study was to investigate the involvement of phytochrome on the germination of achenes of Bidens gardneri Baker., known as black tick. The seeds were separated into short, medium and long sizes. Two experiments used only achenes medium due to differences in the response of germination in the dark, when they were artificially stored in Cerrado soil, in a previous study. The response of achenes short, medium and long to increase flow of white light was observed under a white light gradient from $O$ to $46.44 \mu \mathrm{mol} \mathrm{m} \mathrm{m}^{-2} \mathrm{~s}^{-1}$ creep. The reversal of phytochrome far red (Pfr) in phytochrome red (Pr) in the dark, achenes medium newly collected and stored for 14 months at $4{ }^{\circ} \mathrm{C}$, which were imbibed in water for 24 hours
\end{abstract}

\footnotetext{
${ }^{1}$ Recebido em 20.04.2012 aceito para publicação em 04.06.2012

${ }^{2}$ Universidade Católica Dom Bosco, UCDB, Campo Grande, MS, Brasil. E-mail: <josimararondon@ yahoo.com.br>. ${ }_{3}^{3}$ Departamento de Botanica da Unesp Campus Rio Claro, SP, Brasil. E-mail: <takaki@ unesp.br>.

${ }^{4}$ Instituto de Botânica, Divisão do Jardim Botânico de São Paulo, Seção de Fisiologia e Bioquímica de Plantas. E-mail: <zaidan@uol.com.br>.
} 
and incubated at $35^{\circ} \mathrm{C}$ for 24,48 and 72 hours in the dark and germination was $25^{\circ} \mathrm{C}$ in the dark and observed after 15 and 30 days. Finally, a gradient was constructed photoequilibrium for each size and age of achene in petri dishes moistened with distilled water, and the germination was observed every two days. In irradiances from 0 to $46.44 \mu \mathrm{mol} \mathrm{m} \mathrm{m}^{-2} \mathrm{~s}^{-1}$, germinability of achenes long and medium sizes increased with irradiance, but the seeds had low germination always short. Achenes medium stored imbibed for $24 \mathrm{~h}$ and incubated in the dark for $24 \mathrm{~h}, 48 \mathrm{~h}$ and $72 \mathrm{~h}$ at $35^{\circ} \mathrm{C}$ remained response photoblastic when germination was observed every two days and after 15 and 30 days therefore showed no reversion Pfr for Pr in the dark. However, achenes medium newly collected and subjected to the same treatments were removed when the Pfr incubated for 48 and 72 hours. These achenes showed response very low fluence of light, when germination was observed every two days under green light. The results indicated that heteroblastism can check to the species different strategies of invasion and survival in the savanna: in places with low light availability may occur germination of achenes long, even in the rainy season (February). While short achenes can remain stored in the soil to germinate only come at the end of the dry season (in September). So, the short achene persists in the soil seed bank for seven months and is what allows the establishment of Bidens gardneri at the fields and savannah grasslands.

Keywords: Far red light, phytochromes, heteroblastism and irradiance.

\section{INTRODUÇÃO}

A ação da luz na germinação de sementes é mediada pelo fitocromo em sementes fotossensíveis (CASAL; SÁNCHEZ, 1998). O fitocromo (Phy) é uma família de cinco formas distintas (PhyA, PhyB, PhyC, PhyD e PhyE) codificadas por cinco genes distintos em Arabidopsis thaliana L. e em Lycopersicon esculentum (WHITELAM; DEVLIN, 1997). O fitocromo B é responsável pela detecção da razão entre a luz vermelha e o vermelho-extremo (CASAL; SÁNCHEZ, 1998). Sementes insensíveis à luz, em condições de estresse de água, passam a ter sensibilidade à luz e, segundo Takaki (2001), esse processo é mediado pelo fitocromo A. No entanto, a sensibilidade à luz em sementes de Jacaranda mimosifolia Don em condições de estresse de água foi devida ao fitocromo B (SOCOLOWSKI; TAKAKI, 2004).

Amaral-Baroli e Takaki (2001) verificaram que a germinação dos aquênios de $B$. pilosa com tegumento não ornamentado (aquênios "longos") estaria sob a ação da resposta de fluência muito baixa do fitocromo. Esses autores verificaram que, quando a germinação no escuro era avaliada diariamente sob luz verde, a porcentagem de germinação atingia valor próximo ao do controle na luz branca. Além disso, a germinação era significativamente menor quando se observava o número de aquênios germinados apenas no final do experimento, o que caracterizaria uma resposta de fluência muito baixa.
Respostas de sementes de plantas arbóreas e herbáceas de Cerrado na presença ou ausência de luz foram encontradas em número reduzido de espécies, sendo a maioria indiferente à luz (FELIPPE; SILVA, 1984; SASSAKI et al., 1999ab).

Bidens gardneri Baker, herbácea anual de ocorrência em Cerrados abertos ou na margem de Cerrados mais fechados, à semelhança de B. pilosa, apresenta heteroblastismo. Os aquênios curtos são dormentes quando recém-coletados, e os aquênios longos apresentam germinação alta na luz a $25^{\circ} \mathrm{C}$ (FELIPPE, 1990).

Os aquênios de B. gardneri têm de 7 a 13 mm de comprimento (SASSAKI et al., 1999c). Para seus estudos de germinação com essa espécie, esses autores utilizaram três classes de aquênios: curtos (menores que $9 \mathrm{~mm}$ ), médios ( 9 e $10 \mathrm{~mm}$ ) e longos (acima de $10 \mathrm{~mm}$ ). A relação massa/comprimento dos aquênios curtos é maior que a dos aquênios longos, mas isso não tem correlação com a rapidez de embebição desses dois tamanhos de aquênios (SASSAKI et al., 1999c).

A perda da resposta fotoblástica foi observada em aquênios mantidos sob baixas temperaturas (FELIPPE, 1990). Nesse mesmo estudo, seu autor verificou que, com o aumento do período de armazenamento em frascos de vidro fechados, no escuro a $4{ }^{\circ} \mathrm{C}$, os aquênios de B. gardneri perdem o fotoblastismo, vindo a germinar também no escuro. Quando os aquênios foram armazenados sob solo de mata ou de Cerrado, a fotossensibilidade foi perdida após três meses (SASSAKI et al., 1999c). Rondon et al. (2001) verificaram o efeito

Revista Árvore, Viçosa-MG, v.36, n.6, p.1145-1153, 2012 
do teor de umidade na germinação de aquênios de $B$. gardneri. Aquênios pré-embebidos e armazenados sob temperaturas constantes de $4{ }^{\circ} \mathrm{C}$ e $25^{\circ} \mathrm{C}$ ou alternadas de $20 / 30{ }^{\circ} \mathrm{C}$ germinaram tanto na luz quanto no escuro.

Após o início das chuvas, ocorre formação de flores e frutos em plantas de $B$. gardneri em condições naturais de Cerrado. Quando se encerra a estação chuvosa, as plantas declinam rapidamente, mas seus frutos persistem por longo tempo nas partes secas da haste floral até todos caírem, de modo que o banco de sementes permaneça no solo por cinco a seis meses com o início de um novo ciclo de chuvas (KLEIN et al., 1996).

O banco de sementes do solo pode ser alternativa viável para acelerar o processo de sucessão em áreas onde o solo foi degradado (MARTINS, 2007, 2009b; MARTINS et al., 2009). Porém, não se sabe qual tamanho de aquênio de $B$. gardneri interfere na formação do banco de sementes no solo.

Rondon et al. (2001) observaram que plântulas de B. gardneri costumavam surgir em áreas degradadas por roçada mecanizada ou por fogo colocado pelo homem, no Município de Itirapina, interior paulista. Segundo Rondon (2001), foram localizados vários bancos de sementes dessa espécie em áreas de pastagem na região Centro-Oeste do Estado de Mato Grosso do Sul, evidenciando, portanto, comportamento regenerativo para seu estabelecimento.

Com base nessas informações, a proposta deste trabalho foi verificar qual dos três tipos de aquênio de B. gardneri formaria um banco de sementes do solo que permanecesse no período da estação seca e produziria novos indivíduos na próxima estação chuvosa, bem como avaliar como esses três tipos de aquênios germinavam sob diferentes quantidades e qualidades de luz.

\section{MATERIAL E MÉTODOS}

Os aquênios de Bidens gardneri Baker foram coletados em uma área de Cerrado no Município de Moji-Guaçu (22 $28^{\prime}$ S; $\left.47^{\circ} 11^{\prime} \mathrm{W}\right)$, Estado de São Paulo. Os aquênios foram, então, mantidos a $25^{\circ} \mathrm{C}$ à sombra, por uma semana, e a seguir foram armazenados em frascos de vidro fechados a $4{ }^{\circ} \mathrm{C}$, no escuro.

Os aquênios foram separados em três grupos, conforme seu comprimento (medido com régua milimetrada), em aquênios curtos $(<9 \mathrm{~mm})$, aquênios médios (9-10 mm) e aquênios longos (> $11 \mathrm{~mm})$, conforme Sassaki et al. (1999c). Nos testes de germinação foram feitas três repetições de 30 aquênios, em placas de Petri de $9 \mathrm{~cm}$ de diâmetro, contendo duas folhas de papel-filtro umedecidas com água destilada. A germinação foi feita em câmaras tipo BOD a $25^{\circ} \mathrm{C}\left(+1^{\circ} \mathrm{C}\right)$ sob luz branca fluorescente $\left(46,44 \mu \mathrm{mol} \mathrm{m} \mathrm{m}^{-2} \mathrm{~s}^{-1}\right)$ e no escuro. A germinação no escuro foi observada sob luz verde de segurança (LABOURIAU; COSTA, 1976).

A resposta dos aquênios curtos, médios e longos ao aumento da fluência de luz branca foi verificada sob um gradiente de luz entre 0 e $46,44 \mathrm{~mol} \mathrm{~m}^{-2} \mathrm{~s}^{-1}$ de fluência, obtido com camadas de papel-filtro alternadas com placas de vidro neutro entre a fonte de luz e as placas de Petri contendo os aquênios embebidos. O gradiente de fluência de luz variou entre 0 (escuro) e 46,44 $\mu \mathrm{mol} \mathrm{m}-2 \mathrm{~s}^{-1}$, medindo-se as irradiâncias com um espectrorradiômetro LI-1800 (LI-COR), a $25^{\circ} \mathrm{C}$. Foram considerados tratamentos-controle os limites inferior e superior do gradiente (escuro e luz branca contínua). A germinação foi observada a cada dois dias, durante 30 dias, e os dados do final do período, comparados.

A reversão do fitocromo vermelho-extremo (Fve) em fitocromo vermelho (Fv) no escuro foi avaliada somente em aquênios médios devido às diferenças quanto à resposta de germinação na ausência de luz, quando foram armazenados artificialmente no solo de Cerrado, em um estudo anterior realizado por Sassaki et al. (1999b). Nesse experimento, utilizaram-se os recém-coletados e os que foram armazenados por 14 meses a $4{ }^{\circ} \mathrm{C}$. Esses aquênios foram embebidos em água por $24 \mathrm{~h}$ e, posteriormente, incubados a $35{ }^{\circ} \mathrm{C}$ durante 24,48 e $72 \mathrm{~h}$ no escuro. A seguir, os aquênios foram colocados para germinar a $25^{\circ} \mathrm{C}$ no escuro e a germinação, observada após 15 e 30 dias. A primeira amostra foi observada após 15 dias, e o experimento era descartado. O mesmo procedimento foi adotado para as amostras armazenadas após 30 dias. Quando os aquênios foram germinados à luz, a germinação foi observada a cada dois dias.

A influência do fotoequilíbrio do fitocromo na germinação foi verificada em aquênios curtos, médios e longos recém-coletados e nos que foram armazenados por 14 meses. Foi estabelecido um gradiente de fotoequilíbrio que utilizou duas fontes de luz instaladas a cerca de $150 \mathrm{~cm}$ uma da outra e a $70 \mathrm{~cm}$ da superfície

Revista Árvore, Viçosa-MG, v.36, n.6, p.1145-1153, 2012 
de uma mesa. Uma das fontes de luz apresentava alta relação de V:VE (luz proveniente de duas lâmpadas fluorescentes "luz do dia" de $20 \mathrm{~W}$, filtrada através de uma placa de acrílico vermelha) e a outra fonte de luz, em posição oposta, tinha baixa relação de V:VE (luz proveniente de quatro lâmpadas incandescentes de $25 \mathrm{~W}$, filtrada através de placas de acrílico azuis e vermelhas, superpostas). Cinco faixas foram demarcadas ao longo da superfície da mesa para permitir a emissão dos valores teóricos de fotoequilíbrio: 0,$075 ; 0,15 ; 0,30$; e 0,48 , medidos com espectrorradiômetro (LICOR Instruments, Lincoln, Nebraska, USA) e determinados conforme Mancinelli (1994). Em cada faixa com valores teóricos de fotoequilíbrio predeterminados, para cada tamanho e idade de aquênio foram colocadas quatro placas de Petri com papel-filtro umedecido com água destilada, cada qual com 30 aquênios.

Os dados foram transformados em arco seno $(\%)^{0,5}$ e em seguida as médias foram submetidas à análise de variância (ANOVA) a 5\% de probabilidade. Na comparação entre duas médias, utilizou-se o teste $t$ (SNEDECOR, 1962).

\section{RESULTADOS}

A embebição durante 24 h de aquênios médios recém-coletados, seguida de incubação em temperatura alta $\left(35^{\circ} \mathrm{C}\right)$ por 24,48 e $72 \mathrm{~h}$ no escuro, manteve a resposta fotoblástica, i.e., a germinação na luz foi sempre significativamente mais alta do que em obscuridade (Tabela 1). Após 15 dias no escuro, a porcentagem de germinação foi semelhante à obtida quando os aquênios no escuro eram observados a cada dois dias.
Aquênios embebidos a $35^{\circ} \mathrm{C}$, durante $48 \mathrm{~h}$ e $72 \mathrm{~h}$, e mantidos posteriormente no escuro a $25^{\circ} \mathrm{C}$ mostraram porcentagens de germinação mais elevadas quando comparados com aquênios embebidos por apenas 24 h, nas observações de germinação a cada dois dias e após 15 dias. Entretanto, quando a germinação da outra amostra mantida por 30 dias no escuro foi avaliada, uma porcentagem menor de aquênios germinados foi observada (Tabela 1). Esses resultados indicam que, em aquênios pré-tratados com temperatura alta durante 24, 48 e 72 h, a germinação passa a ser controlada pelo fitocromo, quando a observação no escuro é feita na presença de luz verde de segurança.

B. gardneri armazenados mostraram maior germinabilidade que os aquênios recém-coletados, o que indica que durante o armazenamento no escuro a forma ativa do fitocromo (Fve) é convertida para a forma inativa (Fv). Quando tratamentos semelhantes foram aplicados a aquênios armazenados durante 14 meses, observou-se que o armazenamento reduziu a germinabilidade sob luz (Tabela 2).

A pré-embebição por $24 \mathrm{~h}$ de aquênios armazenados, seguida de incubação em temperatura alta $\left(35^{\circ} \mathrm{C}\right)$ por 24,48 e $72 \mathrm{~h}$, no escuro manteve a resposta fotoblástica, ou seja, a germinação sob luz foi sempre significativamente maior do que em obscuridade (Tabela 2). Após 15 dias e após 30 dias a $25^{\circ} \mathrm{C}$ no escuro, com exceção da amostra incubada por $48 \mathrm{~h}$ a $35^{\circ} \mathrm{C}$, a porcentagem de germinação foi semelhante à obtida nas observações a cada dois dias, o que significa que aquênios armazenados não respondem a fluência muito baixa de luz (luz verde

Tabela 1 - Germinação $(\%)$ na luz $\left(25^{\circ} \mathrm{C}\right)$ e no escuro $\left(25^{\circ} \mathrm{C}\right)$ de aquênios médios de Bidens gardneri recém coletados, avaliados a cada 2 dias, 15 e 30 dias.

Table 1 - Germination $(\%)$ in the light $\left(25^{\circ} \mathrm{C}\right)$ and darkness $\left(25^{\circ} \mathrm{C}\right)$ of Bidens gardneri achenes newly collected (intermediary size) evaluated every 2 days and 15 days and 30 days.

\begin{tabular}{|c|c|c|c|c|}
\hline \multirow{3}{*}{ Embebição (horas) e Incubação $\left(35^{\circ} \mathrm{C}\right)$} & \multicolumn{4}{|c|}{ Germinação (\%) de aquênios recém-coletados } \\
\hline & \multicolumn{2}{|c|}{ A cada 2 dias } & \multirow{2}{*}{$\frac{15 \text { dias }}{\text { Escuro }}$} & \multirow{2}{*}{$\begin{array}{l}30 \text { dias } \\
\text { Escuro }\end{array}$} \\
\hline & Luz & Escuro & & \\
\hline $24 \mathrm{~h}$ & $95,5 \mathrm{aA}$ & $5,5 \mathrm{bD}$ & $1,1 \mathrm{D}$ & $17,7 \mathrm{C}$ \\
\hline $48 \mathrm{~h}$ & 96,6 aA & $57,7 \mathrm{bB}$ & $45,5 \mathrm{~B}$ & $7,7 \mathrm{D}$ \\
\hline $72 \mathrm{~h}$ & $92,2 \mathrm{aA}$ & $44,4 \mathrm{bB}$ & $55,5 \mathrm{~B}$ & $15,5 \mathrm{C}$ \\
\hline $\mathrm{CV}(\%)$ & 2,42 & 75,63 & 85,08 & 38,54 \\
\hline
\end{tabular}

Letras minúsculas comparam germinação na luz e no escuro a cada dois dias (teste t). Letras maiúsculas comparam germinação na luz e no escuro em todos os tratamentos (ANOVA). Minor letters compared germination in the light and darkness each two days ( $t$ test). Major letters compared germination in the light and darkness in all treatments (ANOVA).

Revista Árvore, Viçosa-MG, v.36, n.6, p.1145-1153, 2012 
Tabela 2 - Germinação $(\%)$ na luz $\left(25^{\circ} \mathrm{C}\right)$ e no escuro $\left(25^{\circ} \mathrm{C}\right)$ de aquênios médios de Bidens gardneri armazenados por um período de 14 meses, avaliados a cada 2 dias e de 15 e 30 dias.

Table 2 - Germination (\%) in the light $\left(25^{\circ} \mathrm{C}\right)$ and darkness $\left(25^{\circ} \mathrm{C}\right)$ of Bidens gardneri achenes (intermediary size) stored for 14 months, evaluated every 2 days and 15 days and 30 days.

\begin{tabular}{|c|c|c|c|c|}
\hline \multirow{3}{*}{ Embebição (horas) e Incubação $\left(35^{\circ} \mathrm{C}\right)$} & \multicolumn{4}{|c|}{ Germinação (\%) de aquênios armazenados por 14 meses } \\
\hline & \multicolumn{2}{|c|}{ A cada 2 dias } & \multirow{2}{*}{$\frac{15 \text { dias }}{\text { Escuro }}$} & \multirow{2}{*}{$\begin{array}{l}30 \text { dias } \\
\text { Escuro }\end{array}$} \\
\hline & Luz & Escuro & & \\
\hline $24 \mathrm{~h}$ & 33,3 aA & $12,2 \mathrm{bB}$ & $17,7 \mathrm{~B}$ & $13,3 \mathrm{~B}$ \\
\hline $48 \mathrm{~h}$ & 43,3 aA & $21,1 \mathrm{bB}$ & 7,7 C & $11,1 \mathrm{~B}$ \\
\hline $72 \mathrm{~h}$ & $41,0 \mathrm{aA}$ & $19,9 \mathrm{aB}$ & $15,5 \mathrm{~B}$ & $22,1 \mathrm{~B}$ \\
\hline $\mathrm{CV}(\%)$ & 13,36 & 27,23 & 38,54 & 37,55 \\
\hline
\end{tabular}

Letras minúsculas comparam germinação na luz e no escuro a cada dois dias por 30 dias (teste t). Letras maiúsculas comparam germinação na luz e no escuro em todos os tratamentos (ANOVA). Lower case letters compared germination in the light and darkness every two days during 30 days ( $t$ test). Capital letters compared germination in the light and darkness in all treatments (ANOVA).

de segurança). O fato de os aquênios estarem embebidos durante o período de exposição à temperatura de 35 ${ }^{\circ} \mathrm{C}$ não alterou a germinação na luz e no escuro e, portanto, não houve a reversão do Fve em Fv no escuro.

A germinação dos aquênios longos e médios aumentou conforme elevou a taxa de fluência (Tabela 3). Os aquênios longos atingiram porcentagens de germinação acima de $50 \%$ já com $0,55 \mu \mathrm{mol} \mathrm{m}^{-2} \mathrm{~s}^{-1}$, não ocorrendo aumentos significativos acima desse valor. Sob maior taxa de fluência $\left(46,44 \mu \mathrm{mol} \mathrm{m} \mathrm{m}^{-2} \mathrm{~s}^{-1}\right)$, a porcentagem de germinação dos aquênios médios foi igual à dos aquênios longos. Os aquênios curtos apresentaram germinabilidade baixa, atingindo valores mais elevados apenas a partir de $5,66 \mu \mathrm{mol} \mathrm{m}^{-2} \mathrm{~s}^{-1} \mathrm{de}$ taxa de fluência.

Os aquênios curtos recém-coletados só começaram a germinar com $15 \%$ de fitocromo ativo (Figura 1), mas a germinabilidade permaneceu baixa, independentemente da proporção de fotoequilíbrio fornecida. Já os aquênios curtos armazenados mantiveram-se indiferentes às razões de fotoequilíbrio fornecidas e com baixa germinabilidade, inferior a $10 \%$ (Figura 1).

Os aquênios médios (Figura 1) tiveram comportamento semelhante ao dos aquênios curtos, com germinabilidade próxima a $10 \%$ em todos os valores de fotoequilíbrio fornecidos. Os aquênios médios armazenados germinaram melhor nas razões mais altas de fotoequilíbrio.

Diferenças significativas foram encontradas na germinação de aquênios longos recém-coletados e aquênios longos armazenados (Figura 1). A germinação de aquênios longos armazenados foi significativamente maior na razão de 0,48 de fotoequilíbrio.

\section{DISCUSSÃO}

Estes resultados vêm confirmar os dados anteriormente obtidos por Felippe (1990), em que a porcentagem de germinação dos aquênios curtos foi sempre menor do que a observada nos aquênios longos. Como os aquênios longos germinaram sob baixa taxa de fluência e os aquênios curtos têm baixa germinação, mesmo sob maior taxa de fluência, optou-se por utilizar apenas aquênios médios nos estudos de reversão do Fv em Fve.

Quando aquênios de B. gardneri são tratados com temperatura alta $\left(35^{\circ} \mathrm{C}\right)$ durante 24,48 ou $72 \mathrm{~h}$, a germinação passa a ser controlada pelo fitocromo, e isso foi verificado quando a observação no escuro foi feita na presença de luz verde de segurança, como descrito para B. pilosa (AMARAL-BAROLI; TAKAKI, 2001). E quando armazenados não apresentaram resposta de fluência muito baixa de luz, como ocorre em B. pilosa (AMARAL-BAROLI; TAKAKI, 2001).

No caso de B. gardneri, o período de incubação a $35^{\circ} \mathrm{C}$ que antecedeu o período de germinação a $25^{\circ} \mathrm{C}$ foi insuficiente para reverter o Fve em Fv, indicando que não ocorreu mudança no controle da germinação pelas diferentes formas do fitocromo, como descrito por Takaki (2001). Sementes de Lactuca sativa pré-incubadas a $36^{\circ} \mathrm{C}$ por $24 \mathrm{~h}$ apresentaram baixa germinação a $25^{\circ} \mathrm{C}$ no escuro e baixa reversão do Fve em Fv (TAKAKI; GAMA, 1998). Os resultados indicaram, portanto, diferença de resposta entre aquênios recém-coletados e aquênios armazenados, e apenas os primeiros 
Tabela 3 - Germinação (\%) de aquênios curtos (A), médios (B) e longos (C) recém coletados de Bidens gardneri sob taxas de fluências de luz (irradiâncias) de 0,000 ; 0,$006 ; 0,011 ; 0,55 ; 2,63 ; 3,41 ; 5,66 ; 11,96$ e 46,44 $\mu \mathrm{mol} \mathrm{m} \mathrm{m}^{-2} \mathrm{~s}^{-1}$. Letras comparam germinação em todos os tratamentos de taxa de fluência (ANOVA).

Tabela 3 -Germination (\%) of short achenes (A), intermediary (B) and longer $(C)$ newly collected of Bidens gardneri under light fluence rates (irradiances) of 0.000 ; $0.006 ; 0.011 ; 0.55 ; 2.63 ; 3.41 ; 5.66 ; 11.96$ and $46.44 \mu \mathrm{mol} \mathrm{m} \mathrm{m}^{-2}$. Letters compared germination at all treatments of fluence rate (ANOVA)

\begin{tabular}{cccc}
\hline $\begin{array}{c}\text { Irradiancias } \\
\left(\mu \mathrm{mol} \mathrm{m} \mathrm{m}^{-2}\right)\end{array}$ & $\begin{array}{c}\text { Aquenios } \\
\text { curtos\% }\end{array}$ & $\begin{array}{c}\text { Aquenios } \\
\text { medios\% }\end{array}$ & $\begin{array}{c}\text { Aquenios } \\
\text { longos\% }\end{array}$ \\
\hline 0 & $5 \mathrm{c}$ & $8 \mathrm{c}$ & $38 \mathrm{~b}$ \\
0,006 & $6 \mathrm{c}$ & $8 \mathrm{c}$ & $25 \mathrm{~b}$ \\
0,011 & $7 \mathrm{c}$ & $8 \mathrm{c}$ & $45 \mathrm{ab}$ \\
0,559 & $13 \mathrm{~b}$ & $13 \mathrm{c}$ & $62 \mathrm{a}$ \\
2,632 & $10 \mathrm{c}$ & $39 \mathrm{~b}$ & $80 \mathrm{a}$ \\
3,418 & $8 \mathrm{c}$ & $50 \mathrm{~b}$ & $78 \mathrm{a}$ \\
5,665 & $31 \mathrm{a}$ & $39 \mathrm{~b}$ & $70 \mathrm{a}$ \\
11,96 & $26 \mathrm{a}$ & $39 \mathrm{~b}$ & $80 \mathrm{a}$ \\
46,44 & $26 \mathrm{a}$ & $82 \mathrm{a}$ & $80 \mathrm{a}$ \\
\hline
\end{tabular}
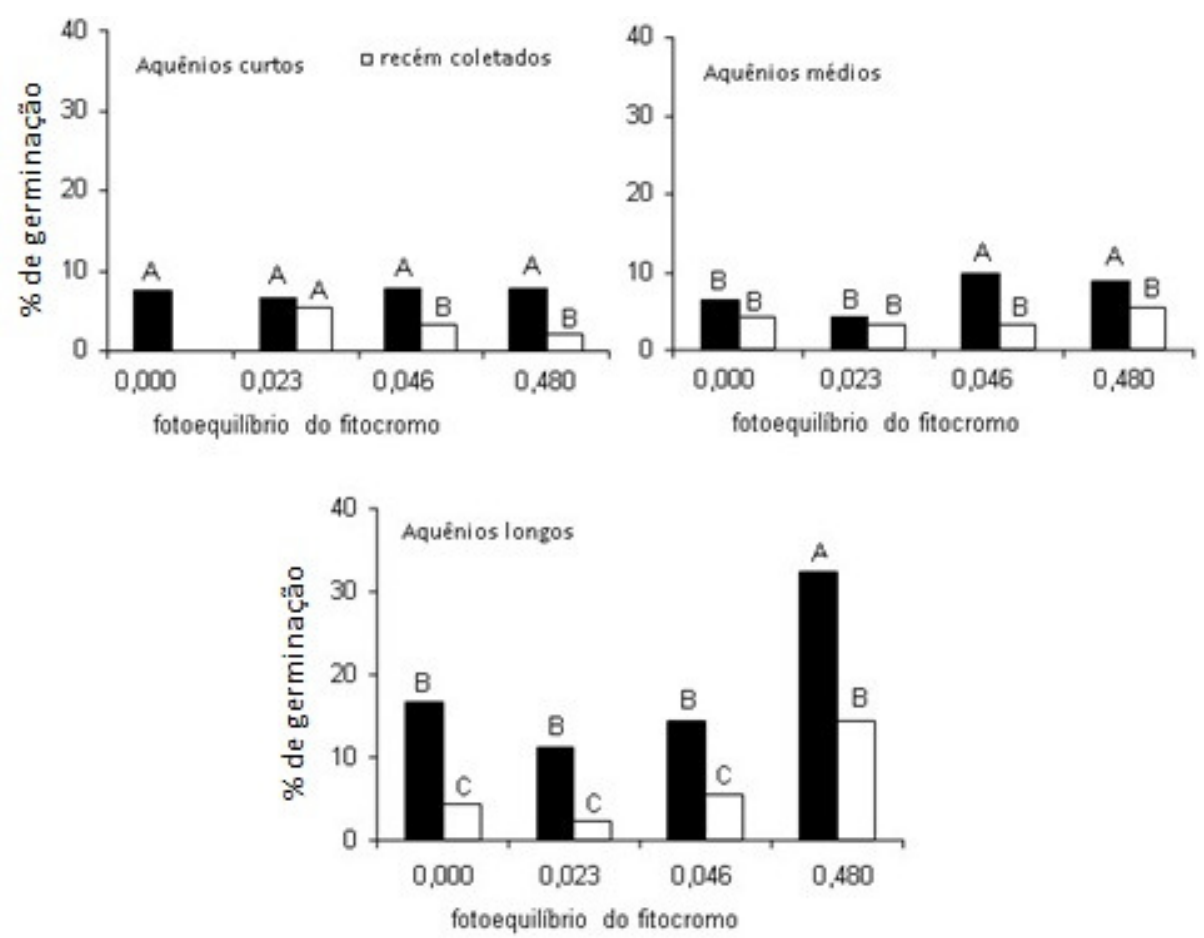

Figura 1 - Germinação (\%) de aquênios curtos (A), médios (B) e longos (C) recém coletados ( $\square$ ) e aquênios curtos, médios e longos armazenados por 14 meses ( $\bullet$ ) de Bidens gardneri sob um gradiente de fotoequilíbrio de Fve/ $\mathrm{F}_{\text {total }}$. Letras comparam germinação ao longo do gradiente (ANOVA) para aquênios recém coletados e armazenados por 14 meses.

Figure 1 - Germination (\%) of short achenes (A), intermediary $(B)$ and longer $(C)$; $\square$ : newly collected or stored for fourteen months (-) of Bidens gardneri under a photoequilibrium gradient (ANOVA). Letters compared germination on the gradient to newly collected plants and stored for 14 months.

Revista Árvore, Viçosa-MG, v.36, n.6, p.1145-1153, 2012

apresentariam resposta de fluência muito baixa do focromo. Esses dados evidenciaram que a inação dos aquênios curtos de B. gardneri não ser controlada apenas pelo fitocromo, mas por A germinação dos aquênios curtos de B. pilosa também não é controlada pelo fitocromo (AMARALBAROLI; TAKAKI, 2001).

Muitas sementes germinam quando incubadas no escuro absoluto, e isso é indicativo de Fve preexistente nas sementes e, ou, que a germinação é independente do Fve (CASAL; SÁNCHEZ, 1998). O fato de respostas ao gradiente de fotoequilíbrio do fitocromo serem somente encontradas em aquênios longos armazenados poderia explicar a perda da sensibilidade à luz após períodos longos de armazenamento a $4{ }^{\circ} \mathrm{C}$ no escuro, descrita por Felippe (1990) e confirmada nos trabalhos de Sassaki et al. (1999ab). 
Os aquênios curtos de B. gardneri possuem tegumento mais espesso que o de aquênios longos, conforme observado em microscopia de varredura (RONDON, 2001). Felippe (1990) observou que ocorria a germinação dos aquênios curtos, após a retirada do tegumento. Isso sugere que o tegumento do aquênio curto possa constituir barreira para a entrada de luz. É possível que durante o armazenamento e, ou, a embebição o tegumento dos aquênios sofra desorganização estrutural suficiente para permitir a entrada de luz. Aquênios longos de B. gardneri recémcoletados devem ter Fve preexistente suficiente para estimular a sua germinação, mesmo quando sob solo. A preexistência de Fve suficiente, interagindo com as temperaturas alternadas e a umidade, ocorrentes no solo de Cerrado no final da estação chuvosa (ORTOLANI; PINTO, 1972), quando acontece a dispersão dos aquênios de B. gardneri, favoreceria a germinação desses aquênios.

A taxa de fluência afetou a porcentagem de sementes germinadas de Cecropia glaziovii (GODOY; TAKAKI, 2005). Todavia, essa influência somente foi significativa entre os valores de fluências de 0,48 e $8,39 \mathrm{~W} \cdot \mathrm{m}^{-2}$ e entre 5,03 e $0,48 \mathrm{~W} \cdot \mathrm{m}^{-2}$. A análise dessa curva de fluência/resposta indicou que as sementes de C. glaviovii apresentam alta sensibilidade à luz, com alta taxa de germinação sob fluência baixa, como 0,48 W. $\mathrm{m}^{-2}$. Segundo Takaki et al. (1985), as curvas de fluência/resposta podem ser utilizadas para compreensão da interação entre luz e outros fatores na indução da germinação. Válio e Scarpa (2001), trabalhando com outras espécies de Cecropia, verificaram que sementes de duas espécies germinavam em ambientes com alta razão V:VE, mantendo o fotoequilíbrio de 0,583 . Esses autores observaram também que em ambiente de luz, em que o fotoequilíbrio do fitocromo é de 0,22 , correspondente à luz filtrada pela vegetação, a germinação foi nula. $\mathrm{O}$ mesmo ocorreu em sementes de $C$. hololeuca Miq., que germinaram somente sob luz branca de alta razão V:VE, enquanto sob luz branca de baixa razão V:VE, que corresponde ao sombreamento pela vegetação e mantém fotoequilíbrio teórico de 0,18 , não houve germinação (GODOY; TAKAKI, 2005).

Sob valores teóricos controlados de fotoequilíbrio, aquênios armazenados, independentemente do seu comprimento, mostraram maior germinabilidade que os aquênios recém-coletados.
Os resultados indicaram que os diferentes tamanhos de aquênios de $B$. gardneri conferem à espécie estratégia interessante de sobrevivência em áreas de Cerrado, por responderem diferentemente à qualidade de luz e, consequentemente, ao fitocromo. Em locais com pouca disponibilidade de luz poderá ocorrer a germinação dos aquênios longos, no final da estação chuvosa, quando há cobertura vegetal. Os aquênios curtos, produzidos em maior número, só deverão germinar no final da estação seca, à chegada das primeiras chuvas, quando há maior irradiação disponível perante a ausência de folhedo nas regiões marginais de Cerrado e de Cerrados abertos, onde as plantas são comumente encontradas.

Os aquênios curtos, armazenados naturalmente no solo, requerem temperaturas entre $25^{\circ} \mathrm{C}$ e $35^{\circ} \mathrm{C}$, um teor de umidade acima de $17 \%$ no interior dos aquênios (massas de matéria fresca e seca obtidas em balança analítica de precisão), e baixos valores de fotoequilíbrio para germinar. O aquênio curto de $B$. gardneri é a única classe de aquênio a permanecer no solo e germinar logo nas primeiras chuvas.

Concluiu-se que, embora o banco de sementes de B. gardneri seja transitório, este é formado predominantemente por aquênios curtos, que demoram mais para germinar, porém, mesmo apresentando baixa germinabilidade, o aquênio curto persiste no solo por sete meses e é o que possibilita o estabelecimento de Bidens gardneri em campos de Cerrado e de pastagens.

\section{AGRADECIMENTOS}

Ao CNPq, pela bolsa concedida; e ao Biota/FAPESP, pelos recursos financeiros.

\section{REFERÊNCIAS}

AMARAL-BAROLI, A.; TAKAKI, M.

Phytochrome controls achene germination in Bidens pilosa L. (Asteraceae) by very low fluence response. Brazilian Archives of Biology and Technology, v.44, n.2, p.121-124, 2001.

CASAL, J. J.; SÁNCHEZ, R. A. Phytochromes and seed germination. Seed Science

Research, v.8, n.3, p.317-329, 1998.

FELIPPE, G. M. Germinação de Bidens gardneri Baker, uma planta anual dos cerrados. Hoehnea, v.17, n.1, p.7-11, 1990.

Revista Árvore, Viçosa-MG, v.36, n.6, p.1145-1153, 2012 
FELIPPE, G. M.; SILVA, J. C. S. Estudos de germinação em espécies do cerrado. Revista Brasileira de Botânica, v.7, n.2, p.157-163, 1984.

GODOY, S.; TAKAKI, M. Efeito da temperatura e a participação do fitocromo no controle da germinação de sementes de embaúba. Revista Brasileira de Sementes, v.27, n.1, p.87-90, 2005.

KLEIN, A. L.; ZAIDAN, L. B. P.; FELIPPE, G. M. Interaction between soil and photoperiod on development of Bidens gardneri Baker (Asteraceae), a herbaceous species from the Brazilian cerrado. Revista Brasileira de Botânica, v.19, n.1, p.1-5, 1996.

LABOURIAU, L. F. G.; COSTA, J. A. F. Objetivos e instalações básicas de um laboratório de fisiologia vegetal. Rio de Janeiro: Academia Brasileira de Ciências, 1976, p.59.

LADEIRA, A. M. et al. Manipulation of seed germination in Plantago tomentosa Lam. and Raphanus sativus L. Seed Science and Technology, v.15, n.1, p.55-63, 1987.

MANCINELLI, A. L. The physiology of phytochrome action. In: KENDRICK, R.E.; KRONENBERG, G. H. M. (Ed.)

Photomorphogenesis in plants. 2.ed., Dordrecht: Kluwer, 1994. p.211-269.

MARTINS, S. V. Recuperação de matas ciliares. Viçosa, MG: Aprenda Fácil, 2007. 255p.

MARTINS, S. V. Recuperação de áreas degradadas: ações em áreas de preservação permanente, voçorocas, taludes rodoviários e de mineração. Viçosa, MG: Aprenda Fácil, 2009a. 270p.

MARTINS, S. V. et al. Colonization of gaps produced by death of bamboo clumps in a semideciduous mesophytic forest in southeastern Brazil. Plant Ecology, v.172, p.121-131, 2004.

MARTINS, S. V. et al. A contribuição da ecologia florestal no desenvolvimento de modelos e técnicas de restauração florestal de áreas degradadas. Revista Ação Ambiental, v.10, n.36, p.10-13, 2007.
MARTINS, S. V. et al. Banco de sementes como indicador de restauração de uma área degradada por mineração de caulim em Brás Pires, MG.

Revista Árvore, v.32, n.6, p.1081-1088, 2008.

MARTINS, S. V. Soil seed bank as indicator of forest regeneration potential in canopy gaps of a semideciduous forest in Southeastern Brazil. In: FOURNIER, M. V. (Ed.) Forest

regeneration: ecology, management and economics. New York: Nova Science Publishers, 2009b. p.113-128.

MARTINS, S. V. et al. Sucessão ecológica: fundamentos e aplicações na restauração de ecossistemas florestais. In: MARTINS, S. V. (Ed.) Ecologia de florestas tropicais do Brasil. Viçosa, MG: Universidade Federal de Viçosa, 2009a. p.19-51.

ORTOLANI, A. A.; PINTO, H. S. Temperatura do solo. In: MONIZ, A. A. (Ed.). Elementos de pedologia São Paulo: Polígono, 1972, p.459.

RONDON, J. N. Efeito do armazenamento na germinação, na resposta do fitocromo e no conteúdo de carboidratos em aquenios de Bidens gardneri Baker, uma espécie herbácea do cerrado. 2001. 75f. Dissertação (Mestrado em Biologia Vegetal) - Universidade Estadual de Campinas, Campinas, 2001.

RONDON, J. N. et al. Effects of moisture content and temperature during storage on germination of the achenes of Bidens gardneri Baker.

Revista Brasileira de Botânica, v. 24, n.1, p.35-41, 2001.

SASSAKI, R. M. et al. Longevity of seeds from legume tree species artificially stores in cerrado and forest soils. Hoehnea, v.26, n.1, p.29-35, 1999a.

SASSAKI, R. M. et al. Germination of seeds from herbaceous plants artificially stored in cerrado soil. Revista Brasileira de Biologia, v.59, n.2, p.271-279, 1999b.

SASSAKI, R. M. et al. Effect of storage of achenes of Bidens gardneri Baker on light sensitivity during germination. Revista Brasileira de Botânica, v.22, n.1, p.75-81, 1999c. 
SNEDECOR, G. W. Statistical methods. Ames:The Iowa University Press, 1962. 168p.

SOCOLOWSKI, F.; TAKAKI, M. Germination of Jacaranda mimosifolia Don (Bignoniaceae) seeds: effects of light, temperature and water stress. Brazilian Archives of Biology and Technology, v.47, n.5, p.785-792, 2004.

TAKAKI, M. New proposal of classification of seeds by forms of phytochrome instead of photoblastism. Brazilian Journal of Plant Physiology, v.13, n.2, p.103-107, 2001.

TAKAKI, M.; GAMA, L. H. P. The role of the seed coat in phytochrome controlled seed germination in Lactuca sativa L. cv. Grand Rapids. Seed Science and Technology, v.26, n.2, p.355-362, 1998.
TAKAKI, M. et al. Interaction of light and temperature on the germination of Rumex obtusifolius. Planta, v.152, n.2, p.209-214, 1981.

TAKAKI, M. et al. Analysis of the effect of light and temperature on the fluence response curves for germination of Rumex obtusifolius. Plant Physiology, v.77, n.2, p.731-734, 1985.

WHITELAM, G. C.; DEVLIN, P. F. Roles of different phytochromes in Arabidopsis photomorphogenesis. Plant Cell and Environment, v.20, n.6, p.752-758, 1997.

VÁLIO, I. F. M.; SCARPA, F. M. Germination of seeds of tropical pioneer species under controlled and natural conditions. Revista Brasileira de Botânica, v.24, n.1, p.79-84, 2001. 
